\title{
Uma alegoria nacional \\ Respiración artificial: vinte anos depois
}

Rita de Grandis

Não me proponho repetir o que já se disse amplamente sobre um tex to tão estudado como Respiración artificial*. Situarei a minha leitura numa perspectiva que não difere totalmente da que assumi na década de 1980, embora a inclua na medida em que me identifico com determinadas atitudes ideológicoformais e metodológicas.

Tanto dentro como fora do país, Respiración artificialfoi uma obra analisada em relação aos horrores do panóptico do estado terrorista argentino. Quanto à sua estrutura formal, e não obstante as declarações do próprio autor, um setor da crítica vinculou o romance à metaficção pós-moderna, dados os processos de citação e de auto-referencialidade que o texto adota e que caracterizam a chamada estética pós-moderna*.

Poucas vezes irrompe no panorama intelectual um romance com um impacto comparável ao de Respiración artificial, pelo menos desde a época do Boom, quando a literatura decididamente interpelava o campo intelectual. Respiración artificial foi composto e publicado durante o Processo (1976-1983) - assim denominado pelo próprio regime então vigente. Contudo, foi somente depois desse período que se tornou possível o aparecimento da crítica. O relato aborda, direta ou indiretamente, a problemática política desse momento histórico da Argentina e pode comparar-se sob certos aspectos a Cuerpo a cuerpo de David Viñas, embora este tenha sido publicado no México*.

A minha leitura de Respiración artificial na década de 1980 fora, por um lado, auto-centrada, pois atendia aos procedimentos de produtividade e à intertextualidade como princípios normativos de composição e produção de significados; por outro lado, abordava a questão nacional, isto é, analisava os meios servidos no relato para dialogar e estabelecer uma relação polêmica não só com as diatribes culturais e ideológicas vanguardistas, mas também com o sistema literário argentino no seu conjunto e, particularmente, com os debates travados no século
" (Piglia, Ricardo. Respiración artificial. Cuba: Casa de las Américas, 2000)

" (Morello-Frosch, Marta. "Significación e Historia en Respiración artificial. De Ricardo Piglia". Em: Fascis. mo y experiencia literaria: Reflexiones para una re. canonización. Minnesota: Institute for the Study of Ideologies and Literatures, 1985: 489-500; Pons María Cristina. Más allá de las fronteras del lenguaje. Un análisis crítico de Res piración artificial de Ri cardo Piglia. México: Uni versidad Nacional Autó noma de México, 1998; Maristany, José Javier. Narrraciones peligrosas: resistencia y adhesión en la época del Proceso. Buenos Aires: Biblos, 2000; Colás, Santiago. Postmodernity in Latin America. The Argentine Paradigm. Durham and London: Duke University Press, 1994)

" (Bratosevich, Nicolás y Grupo de Estudio. Ricardo Piglia y la cultura de la con. travención. Buenos Aires: Atuel, 1997: 125) 
- (De Grandis, Rita. Polé mica y estrategias narrativas en América Latina. Argen tina: Beatriz Viterbo Edi. tora, 1993)

(Anderson, Benedict. Comunidades imaginadas. Buenos Aires: Fondo de Cultura Económica, 2000)

"(De Grandis, Rita. Polémica y estrategias narrativas en América Latina. Op. cit. Terán, Oscar. Nuestros años sesentas. Buenos Aires: Pun tosur, 1991; Sigal, Silvia. Intelectuales y poder en la década del sesenta. Buenos Aires: Puntosur, 1991)
XIX acerca das origens da nação moderna*. Tal leitura identificava a referida polêmica como uma linha de força, uma estrutura argumentativa e um tropo da "imaginação” nacional para usar a terminologia de Benedict Anderson*. Dentro desta perspectiva, havia que se buscar a significação do romance, o contexto da sua enunciação e as condições da sua produção no intertexto privilegiado que constituiu a Revolução Cubana, a qual, considerada como pauta de interpretação ideológica, possibilitou as leituras "marxistas", "revisionistas" ou "revolucionárias" do peronismo realizadas no grupo Contorno durante os anos 1950 e 1960 até o esgotamento de tais interpretações nos fins de 1970 e 1980, quando se dá a queda do governo peronista e das democracias sociais do continente*.

Nessa arena de posições e contraposições estético-ideológicas, a novidade da narrativa proposta por Ricardo Piglia consiste na singular interpretação que nela se oferece como síntese superadora desses velhos embates ideológicos e estéticos ${ }^{1}$. Para mais, tal síntese se realiza por vias estritamente literárias, através das figuras de Arlt e Borges em particular, os quais personificam para Piglia o paradoxo nacional moderno. A partir dessa perspectiva, Arlt é o escritor verdadeiramente moderno na literatura argentina do século XX, e Borges um escritor que fecha o século XIX. Assim, à interpretação antitética de Arlt versus Borges intentada em Contorno, outra se lhe segue, à base de mútua interdependência, de ironia e de necessidade dialéctica. Se a modernidade de Arlt consiste em ter escrito fora dos parâmetros da exegese europeísta, posto que lhe faltavam essa aspiração e o bilingüismo arrogante dos escritores decimonônicos, a de Borges está em valer-se destas mesmas pretensões como instrumentos de requintada ironia literária. Eis como Piglia anula a interpretação "parricida” da geração de Contorno, pela qual Borges é demonizado, e Arlt aparece como a sua contrapartida: cara e coroa da mesma moeda. Em ambos os escritores se condensa a polêmica vigente no campo intelectual perante o imperativo ideológico contido no compromisso sartreano do escritor com a sua época, que tanto caracterizou esse período.

\footnotetext{
${ }^{1}$ Esta síntese superadora de conflitos não é privativa de Respiración artificial; está presente noutras obras do autor: contos como "Luba" e "Las actas del juicio", os ensaios de Crítica y ficción e várias de suas entrevistas (que constituem em si mesmas um dos gêneros praticados pelo escritor) são bons exemplos desta proposta narrativa.
} 
Assim, Piglia propõe um juízo crítico das ditas interpretações, configurando um novo padrão estético e ideológico que, ao desmanchar os anteriores, invalida os fundamentos dessa modalidade cultural própria e terá ressonâncias particulares nas décadas posteriores à ditadura.

Sem perder de vista a ênfase estético-ideológica, hoje a minha atenção dirige-se outra vez à questão nacional, pois Respiración artificialnão só proporciona re-leituras e re-escrituras mediante as quais o século XIX se inscreve no romance, mas também abre caminho igualmente a um sem-número de novas interpretações desse século durante os anos 1980 e, especialmente, os anos 1990.

O século XIX converteu-se assim em chave interpretativa dos males nacionais, diagnosticados em notas periodísticas e no campo da ficção narrativa, como bem o exemplifica uma parte da produção literária de Beatriz Sarlo, José Pablo Feinmann e Andrés Rivera. Inclusive um certo tipo de literatura feminina destas últimas décadas voltou os olhos para o século XIX a fim de desenterrar os amores dos nossos ilustres antepassados ${ }^{2}$.

Na década de 1980, e sobretudo no último lustro de 1990, o século XIX impôs novamente a sua presença dominante como pauta de referência explicativa e comparativa em textos de periódicos, ensaios e novelas de autores argentinos. Numa nota dirigida ao jornal Clarín em maio de 2000, Beatriz Sarlo esboça uma analogia entre Alberdi e o panorama argentino atual, marcado pelas profundas diferenças entre Buenos Aires e o resto do país no que diz respeito ao leque político e à representatividade das novas alianças políticas entre o radicalismo e o Frepaso. A comparação com Alberdi baseia-se numa feição política que ele já tinha antecipado e que se projeta no momento presente: para Alberdi, a Revolução de Maio dera origem à divisão entre Buenos Aires e o interior do país*. É curioso notar que esta mesma alusão a Alberdi e aos políticos da Geração de Maio constitui um dos pontos centrais adotados por Feinmann no ensaio La sangre derramada, ao desenvolver a sua tese acerca da insuficiência histórica da modernidade argentina.

\footnotetext{
${ }^{2}$ Refiro-me a La amante del restaurador, de María Esther de Miguel (1998), a Ana y el Virrey, de Silvia Miguens (1998), entre outros romances. Também a primeiras edições em castelhano de relatos do século XIX, como Pablo o la vida en las pampas, de Eduarda Mansilla de García, o primeiro romance de uma mulher argentina escrito em francês em 1868.
}

" (Sarlo, Beatriz. "Yo he nacido en Buenos Aires". Em: Clarín-Zona. Domingo 14 de mayo de 2000: 5) 
- (Diego, José Luis de. Quién de nosotros escribirá el Facundo?. Intelectuales y escritores en Argentina, 1970-1986. La Plata: Edi. ciones Al Margen, 2001)
Reler Respiración artificial na atualidade implica conceber este romance não como uma mera resposta codificada ao Processo, mas sim como algo que participa integralmente no particular dinamismo que impulsa a literatura nacional neste momento do seu desenvolvimento histórico, assinalado pela continuação, consolidação e crise dos processos democráticos internos, num quadro internacional em que domina uma economia de livre câmbio e de corte liberal, com efeitos diretos no desenvolvimento das democracias locais.

Nesta conjuntura histórica, tanto Respiración artificialcomo La ciudad ausente (1992), bem como alguns contos de Piglia, ocupam uma posição-chave no campo intelectual e mantêm o seu valor de textos fundamentais para a compreensão não só da década de 1980, como assinala José Luis de Diego, mas também da de 1990 e do que abrange o século XXI. Em ¿Quién de nosotros escribirá el Facundo?(1990) - esse título é uma frase colhida de Respiración artificial - J. L. de Diego* corrobora a preeminência de Ricardo Piglia no próprio centro do campo literário dos anos 1980, "por sus operaciones críticas de recanonización de escritores del pasado y de canonización de algunos de sus contemporáneos”- de Rodolfo Walsh e Manuel Puig, de Andrés Rivera e de Juan José Saer; por intervir com Respiración artificial e Crítica y ficción nos legados literários de Arlt e Borges; por restaurar o valor de Macedonio em numerosos artigos críticos e mais tarde em La ciudad ausente; e, finalmente, pela atitude quase desdenhosa de Piglia em relação a Cortázar.* Por sua vez, muitos escritores exilados puseram igualmente em relevo o papel central desempenhado por Ricardo Piglia, embora alguns deles, como Osvaldo Soriano e Tomás Eloy Martinez, considerassem a sua obra poética "demasiado intelectualizada y por momentos hermética”* Nicolás Bratosevich, por outro lado, afirma que Respiración artificiale La ciudad ausente tecem “sobre un nuevo círculo de volcán”, por meio duma urdidura indireta, o mapa político-social da Argentina actual*.

\section{Por uma literatura nacional em tempos de democracias globais}

Segundo Anderson, por estranho que pareça, numa época caracterizada por uma visão negativa dos nacionalismos, quando “es tan común que los intelectuales progresistas, cosmopolitas (sobre todo en Europa?) insistan en el temor y el odio a los 
otros, y a sus afinidades con el racismo, convendrá recordar que las naciones inspiran amor, y a menudo un amor profundamente abnegado"* . Visto dum ângulo crítico diferente, e dentro do debate suscitado pela noção de pós-colonialismo, particularmente na tradição britânica, existe um tipo de literatura - como a de Salman Rushdie na Inglaterra e a de Michael Ondaatje no Canadá, para citar os mais conhecidos - que de alguma maneira se pode conceber como não-nacional. Essa classe de escritores representa os movimentos migratórios e diaspóricos das últimas décadas do século XX, e o que vai do XXI, que tornaram ainda mais complexa a questão nacional. Contrapondo-se a estas tendências, ergue-se essa outra literatura, a qual só se pode conceber dentro das suas próprias fronteiras nacionais.

Em grande parte, a vigência de Respiración artificial e, em especial, a sua persistente ressonância nas décadas posteriores à ditadura devem-se precisamente ao caráter nacional inscrito no romance, caráter este que há de marcar toda uma gama de produções literárias e estéticas - em particular La sangre derramada, de José Pablo Feinmann -, revelando uma vez mais a ambigüidade inerente à literatura, à política dos gêneros e suas estéticas de apropriação. Em Encuesta a la literatura argentina contemporánea, Piglia* afirma que só se pode pensar uma obra no interior da literatura nacional, porque é a partir desse espaço que se "organiza, ordena y transforma la entrada de los textos extranjeros y $[\ldots]$ se define la situación de lectura"** Esta idéia há de governar o desenvolvimento do enredo em Respiración artificial, posto que a adoção do modelo europeu será o eixo temático com base no qual os personagens discorrem e fazem o juízo crítico da cultura e da literatura nacionais** Como assinala Anderson com referência ao caso das Américas, tal europeísmo havia permitido essas “vidas paralelas” da primeira intelligentzia crioula, por quanto significou compartilhar uma língua, uma religião e uma cultura com as metrópoles sob cuja égide, paradoxalmente, se tinha tornado possível criar as primeiras imagens nacionais e independentistas, no instante mesmo da ruptura com essas metrópoles. É desta tensão entre ruptura e continuidade que nasce e se desenvolve a "imaginação” nacional, considerada como uma das modalidades próprias de interpretação*. Em Respiración artificial o retorno ao século XIX permite inscrever e ligar o presente de enunciação da narrativa - fins da década de 1970 - com as origens do esta-
" (Anderson, Benedict. Co. munidades imaginadas. Op. cit.: 200)

"(Piglia, Ricardo. Encuesta a la literatura argentina contemporánea. Buenos Aires: Centro Editor de América Latina, 1981 137-140)

"(: 137)

"(De Grandis, Rita. Polémica y estrategias narrativas en América Latina. Op. cit.: 122 124)

" (Anderson, Benedict. Co. munidades imaginadas. Op. cit.: $270 \cdot 272$ 
"(Pons, María Cristina. Más allá de las fronteras del lenguaje. Un análisis crítico de respiración artificial de Ricardo Piglia. México: Universidad Nacional Autóno ma de México, 1998)

"(Piglia, Ricardo. Respira. ción artificial. Prólogo de Jorge Fornet. Cuba: Casa de las Américas, 2000.: 16)

- (Bratosevich, Nicolás y Grupo de Estudio. Ricardo Piglia y la cultura de la con. travención. Op. cit.: 152) do moderno. Ora bem, no cenário democrático montado após a ditadura, esse século XIX convida agora a ler-se não como uma alegoria do Processo mas antes como uma incessante interrogação acerca do estado, da nação e da literatura que o novo contex to da sua leitura, inevitavelmente cronóptica, inaugura. Deste modo, o século XIX estabelece uma relação dialética entre os liberalismos de ambos os séculos, e, desta relação, emana uma determinada consciência histórica que ilumina a inteligibilidade da sua nova temporalidade de leitura. À volta desse século e através do mesmo, um importante debate se concentra no campo intelectual sobre as relações entre estado e nação, democracia e governo, cultura e literatura. Ao analisar certos acontecimentos ocorridos durante a época de Rosas, o autor de Respiración artificial continua a tarefa de Sarmiento, Mármol, Alberdi e outros, e vai dessa maneira procurar no passado as raízes do presente, visto "como episodio insertado en la corriente de la historia nacional, o como fruto de una involución patológica”*

$\mathrm{E}$ a figura do novo intelectual que se vai esboçando, tal como a do século XIX, faz questão de participar ativamente na gestação da nação. Eis por que na pós-data de uma das cartas que Arocena reorganiza, o narrador cita: "A veces (no es joda) pienso que somos la generación del 37. Perdidos en la diáspora. Quién de nosotros escribirá el Facundo?"*- uma interrogação que não alude a toda uma geração de intelectuais que se identificam com os seus predecessores no ato de reafirmar um lugar de pertença e de autolegitimação.

A inscrição do século XIX em Respiración artificial evidenciase nos procedimentos formais que o romance utiliza, como, por exemplo, a inclusão de diversos gêneros narrativos. Emilio Renzi manifesta o seu desejo de escrever uma novela epistolar, gênero decimonônico bastante popular. Como este, predominam também "otras formas narrativas como la biografía o autobiografía, el diario, la narración dialogada ...”*. O próprio Piglia, assinala Fornet, pretendia dar à sua obra a forma dum fichário ou duma caixa que contivesse materiais diversos, tais como diários, cartas e documentos, para melhor poder elaborar sobre o tema da história do século XIX*. Quanto ao gênero utópico, Bratosevich recorda-nos que "Piglia no sólo vuelve a derribar la apretada concepción clásica de utopía, sino también la romántica de nuestro siglo XIX, sustituyéndolas por el Deseo de un futuro de liberación $[\ldots .$.$] a cuyo sostén se aferra su escritura"**. Em Respira-$ 
ción artificial recupera-se o pensamento utópico que havia dominado a Europa dos séculos XVIII e XIX, e que vai marcar a trajetória intelectual da geração de 37 , tanto nos que estiveram estreitamente relacionados com ela como nos que tivessem aderido tangencialmente aos postulados básicos da dita geração: "Echeverría, Sarmiento e Alberdi transitan un discurso utópico que, a pesar de que se distancia de las convenciones, preserva el espíritu crítico de sus congéneres"* . A reutilização do gênero utópico, disseminado pelas páginas de Respiración artificial, tal como nos seus antecessores decimonônicos, configura cenas ou núcleos em cujos textos se pode ler um modelo de país, um tipo de fundação: "El tiempo 'real' de la novela irá desde marzo de 1837 a junio de 1839 (Bloqueo francés, Terror). Durante ese lapso, por medio de un procedimiento que debo resolver, el protagonista encuentra (tiene en su poder) documentos escritos en la Argentina de 1979. Reconstruye (imagina) al leer, cómo será esa época futura"*.

Assim, ao reutilizar procedimentos narrativos e contextos históricos do século XIX, Respiración artificial mantém a sua continuidade com a literatura dos alvores da nação e sua relação dialéctica com a mesma e com aquele século como chave para a interpretação do presente.

\section{A inscrição do século XIX numa nova alegoria nacional. Defesa da alegoria.}

Como tínhamos antecipado, a dimensão alegórica ou quasealegórica de Respiración artificial com relação ao Processo foi estudada, entre outros, por Kathleen Newman y Santiago Colás. Kathleen Newman afirma que, se o romance conseguiu publicarse na Argentina isento de censura, deve-se ao caráter alegórico que se depreende da sua estructura narrativa, o qual chama a atenção de leitores altamente educados, capazes de decifrar a referencialidade do texto. A composição do romance - integrado por cartas, fragmentos de diários, conversas contadas em outras conversas (estilo indireto), e alusões filosóficas e literárias - possibilitou uma clara leitura condenatória dos militares e paramilitares. O leitor está ciente de que Piglia conta a história de Maggi para expor os acontecimentos mais recentes e também para abordar a história da esquerda política. Assim, a pergunta com que se inicia o romance: “¿Hay una historia?" não se refere somente à tragédia de Maggi mas à inteligibilidade
" (Rodríguez Pérsico, Adri. ana. Un huracán Ilamado progreso: utopía y auto biografía en Sarmiento y Alberdi. Washington: Inter. mer, OEA, 1993: 7) 
(Newman, Kathleen "Historical Knowledge in the Post-Boom Novel". Em: The Historical Novel in Latin America: a Symposium. Ediciones hispamérica, 1986 217)

* (Bratosevich, Nicolás y Grupo de Estudio. Ricardo Piglia y la cultura de la con. travención. Op. cit.: 129)

(Newman, Kathleen "Historical Knowledge in the Post-Boom Novel". Em: The Historical Novel in Latin America: A Symposium. Op. cit.: 217) da história argentina. Por isso tem que se ler Respiración artificial como um romance político/policial. "Nadie sabe leer. Porque para leer, dijo Tardewski, hay que saber asociar"*. Além disso, para Newman, as diversas e contraditórias textualidades com que Piglia constrói uma filosofia da história significam um distanciamento da definição marxista de mudança histórica na qual se haviam apoiado as operações esquerdistas nos anos de 1960 e 1970. Por seu lado, Nicolás Bratosevich assinala que Respiración artificial orienta obliquamente ao leitor para que entenda o próprio romance como "otro (anti)diálogo con el discurso de la dictadura. La historia se construye como 'ocultamiento de un relato' (frase tomada de uma declaração de Tomás Eloy Martínez em Página 12, 28-II-93)"** De maneira semelhante, Santiago Colás regressa à pergunta inicial da novela - "Hay una historia?"- e na resposta - "En abril de 1976" - identifica uma dimensão alegórica referida ao Processo. Embora a sua análise não se concentre neste tema, acaba inevitavelmente por incluí-lo na descrição das alusões tangenciais aos crimes ocorridos.

A relação entre tio e sobrinho constitui um modelo dessa história familiar, a qual se desvia das normas estabelecidas na medida em que não corresponde nem ao modelo de família tradicional nem ao contido no discurso da História sustentado pelos militares. Respiración artificial faz deslocar a ambos os modelos genealógicos e propõe substituí-los por uma genealogia a bem dizer incompleta, que procede de tio (Maggi) a sobrinho (Renzi) e que se justifica ademais com um discurso da crítica ou teoria literária: "Alguien, un crítico ruso, el crítico ruso Iuri Tinianov, afirma que la literatura evoluciona de tío a sobrino (y no de padres a hijos)"** Trata-se de uma genealogia que vai também de genro (Marcelo Maggi) a sogro (Luciano Ossorio): ambos compartilham a mesma paixão pela história.

Além disso, a paternidade manifesta-se como ausência: Luciano Ossorio não conhecera o seu pai porque este fora morto num duelo para proteger o seu avô, Enrique Ossorio. Enrique, por seu lado, também não tinha conhecido o seu pai, que morrera antes do nascimento do seu filho, o qual, ademais, era fruto duma relação ilegítima e incestuosa com uma prima sua. Tratase, pois, duma genealogia feita de desvios na estrutura do parentesco, e só um leitor treinado à guisa dum detective dos romances político-policiais de que nos fala Newman poderá encontrar as pistas ocultas e decifrar os enigmas*. 
Além do mais, a significação alegórica torna-se ainda mais evidente quando atentamos a outro dos importantes procedimentos formais presentes na novela: a citação e as suas ambigüidades, pois as citações vão-se dispondo como o encontro frustrado entre Emilio Renzi e o seu tio desaparecido, Marcelo Maggi. Ao mesmo tempo, a urdidura dessas citações, como apropriação de textos alheios, constitui a maneira própria de edificar a narrativa*. Também María Cristina Pons e Marta Morello-Frosch descobrem no romance uma leitura alegórica do presente histórico, afirmando que "el entretejido o yuxtaposición de historias, ideas, reflexiones e citas hace posible que, apesar del cambio de las voces narrativas, 'la historia' sea la que mantiene el hilo conductor del texto, más que las voces narrativas básicas"*. A tarefa narrativa de ordenar os dados e explicá-los a partir de textos pré-existentes que configuram um novo discurso traz à tona e atualiza o passado, reconstituindo uma nova significação para um novo grupo de leitoresintérpretes*. Por último, para Daniel Balderson, Piglia considera que a sua missão como romancista é a de insuflar nova vida nos mortos e nos agonizantes na Argentina: dar voz aos desaparecidos, ressuscitar o passado. Eis aqui uma metáfora desesperada mas apropriada para o contexto narrativo*.

A té este ponto esboçamos algumas das interpretações de Respiración artificial relativas à questão nacional e ao que o romance tem de alegórico com referência ao Processo.

\section{Respiración artificial como novela de fundação}

Se bem que estas leituras de sentido alegórico ou quasealegórico - alegoria entendida aqui mais como uma relação metafórica que metonímica ${ }^{3}$ - sejam perfeitamente plausíveis, encontramo-nos hoje, como assinala Bratosevich, em circunstâncias suficientemente novas "para refrendar aquella opinión sobre lo parcial de la explicación por el expediente de la autocensura en la novela pigliana del ochenta"* Estamos bastante

\footnotetext{
${ }^{3}$ Para Doris Sommer, a alegoria, em vez de designar uma relação metafórica paralela de um termo por outro (amor por política, erotismo por nacionalismo), designa uma relação metonímica onde um termo se sobrepõe a outro. A crítica de Sommer consiste principalmente em que tal divisão esteja motivada por certa culpa diante das dificuldades de leitura que oferecem as literaturas do "Terceiro Mundo". Além disso, certo véu exótico parece recobrir a literatura do "Terceiro Mundo", e, na realidade, esta noção acaba sendo bastante abarcadora - há textos que não são alegorias nacionais - e bastante estreitas - já que ainda se escrevem
}

*(De Grandis, Rita. “La cita como estrategia narrativa en Respiración artificial." Em: Revista Canadiense de Estudios Hispánicos (2) 1993: 259-269; Colás. Santiago. Postmodernity in Latin America. The Argen tine Paradigm. Durham and London: Duke University Press, 1994: 121-148)

" (Balderston, Daniel. “La. tent Meanings in Ricardo Piglia's Respiración arti. ficial and Luis Gusmán's En el corazón de junio." Em: Revista Canadiense de Estudios Hispánicos (2) 1988: 215)

" (Bratosevich, Nicolás y Grupo de Estudio. Ricardo Piglia y la cultura de la con. travención. Op. cit.: 126) 
" (Franco, Jean. Plotting Women: Gender and Representation in Mexico. New York: Columbia University Press, 1991; Sommer, Doris. Foundational Fictions. The National Romances of Latin America. Berkeley, Los Ange les, London: University of California Press, 1991; Rodríguez Pérsico, Adriana. Un huracán Ilamado progreso. Utopía y autobiografía en Sar. miento y Alberdi. Op. cit.) afastados já dos primeiros anos do Processo; o sistema constitucional democrático desfruta duma duração antes desconhecida na Argentina e, por conseguinte, as possíveis interpretações do romance ultrapassam agora o âmbito de referências ao Processo.

O século XIX, graças aos procedimentos formais em clave paródica então postos em prática, tais como o relato familiar e genealógico, a relação família-estado, o gênero epistolar, o romance utópico, a anotação em forma de arquivo, abre ao campo intelectual na sua totalidade todo um mundo dinâmico de interpretações. A alegoria e a fundação, de um modo particular, mantêm uma relação estreita e produtiva com respeito à literatura latino-americana do século XIX, como foi estudado, entre outros, por Jean Franco, Doris Sommer e Adriana Rodríguez Pérsico*.

Apesar do seu hermetismo referencial, a publicação de Respiración artificial não só coincide com a abertura do ciclo democrático na Argentina dos anos 1980, mas emana também desse inextricável enlace entre política e ficção que deu origem aos mais importantes textos da imaginação nacional no século XIX, estabelecendo com eles uma singular filiação e confirmando a intenção fundadora que o romance comporta. Deste caráter fundador desprende-se uma vontade reparadora não com o intuito de harmonizar as partes em discórdia e oferecer uma reconciliação - diríamos "la obediencia debida," como assinala Doris Sommer a propósito dos "romances fundacionais" - (Soledad, de Mitre,e Amalia, de Mármol), senão como sintoma duma ausência a que a literatura tenta dar um nome.

O grande êxito comercial e a consagração crítica de Respiración artificial não se devem aos seus méritos como obra de

alegorias nacionais no "Primeiro Mundo", como ocorre com Pychon e Grass, entre outros. Para Sommer, a combinação de alegoria e dialética - embora pareça um oxímoro para leitores habituados a definições convencionais - foi a base pela qual Benjamim tentou recuperar o conceito para a escritura histórica contra a noção de símbolo, na polêmica com os românticos (Sommer, Doris. Foundational Fictions. The National Romances of Latin America. Op. cit. 42-43). Para Aijaz Ahmad, a descrição e a definição que Jameson faz das literaturas dos países "subdesenvolvidos" como alegorias nacionais revelam o etnocentrismo e a miopia cultural das humanidades nos Estados Unidos, além de totalizar um fenômeno histórico em termos de oposições binárias (nacionalismo/pós-modernismo neste caso), como se o nacionalismo fosse uma unidade homogênea (Ahmad, Aijaz. “Jameson's rhetoric of otherness and the National allegory”. Em: Ashcroft, Bill et al (ed.). The post-colonial studies reader. London and New York: Routledge, 1995, p. 77-84). 
entretimento, mas antes ao fato de ter desenvolvido uma fórmula estético-ideológica visando explicar os conflitos incessantes que afligem a Argentina, convidando assim as esferas intelectuais implicadas nos sucessos políticos dos anos 1970 a desentranhar a complexidade da sua própria história fratricida. A intenção fundadora em que se assenta a novela, evidente após a sua leitura esclarecida, está indicada textualmente pela referência temporal a abril de 1976 - data convertida num emblema que proporciona uma conexão essencial com o real histórico. ${ }^{4}$ Este tropo evoca inevitavelmente outro excepcional relato de tipo fundacional: "La noche del cuatro de mayo de 1840 a las 10 de la noche"*, o começo de Amalia, cuja data o leitor associa irremediavelmente à intensificação do terror rosista contra a elite tradicional, do mesmo modo que o 24 de abril de 1976 está ligado à tomada do poder por parte da Junta militar em 24 de março desse ano. Em Respiración artificial, a data em questão não só lança os fundamentos da história do Processo: ela inscreve, além disso, o relato numa tradição literária nacional e manifesta sobretudo a sua vontade de adesão a essa comunidade nacional.

Enrique Ossorio é esse personagem dúplice, possível agente duplo de Rosas, anti-rosista a serviço de Rosas. Ele faz lembrar Daniel Bello, herói de Amalia, que representa também um personagem dúplice a serviço de e contra Rosas, embora, na realidade, esteja longe de ser um herói, já que as suas táticas são as de alguém que resiste, afirmando com a palavra o que logo desmente com os atos: um personagem cujos pragmatismo e astúcia, como meios de sobrevivência, condizem com o comportamento político da época: "En cuanto a mí nací Enrique de Ossorio, pero he desechado esa partícula cuyas resonancias ofenden la razón de mi época: las virtudes del linaje no me parecen a la altura de los tiempos, ni de mis ambiciones, y prefiero dármelo todo a mí mismo. En cuanto a mí, Enrique Ossorio, he sido un traidor y un espía y un amigo desleal y seré juzgado tal por la historia, como soy así juzgado por mis contemporáneos”**.
" (Mármol, José. Amalia. Buenos Aires: Centro Editor de América Latina, 1967: 5)

${ }^{4}$ Data que, como assinala Adriana Rodríguez Pérsico para as Bases de Alberdi, não só indica um fato mas também representa uma totalidade: "Mayo, la historia, la idea, la tradición, la infancia y también la primera gran fractura que divide los tiempos de la patria en un antes y un después, forja en moldes indelebles la identidad nacional” (Rodríguez Pérsico, Adriana. Un huracán llamado progreso. Utopía y autobiografía en Sarmiento y Alberdi. Op. cit. 57). 
Além disso, o fato de Enrique Ossorio refugiar-se na casa de sua prima pode bem estar relacionado com a história de Eduardo Belgrano, o qual busca igualmente refúgio na casa de Amalia, prima de Daniel. Assim, ao mesmo tempo que estabelece uma conexão com Amalia, o romance de Piglia desliga-se dos seus procedimentos formais e ideológicos, posto que se afasta do panfletarismo do século XIX, o qual, embora fosse com freqüência brilhante, pecava sobretudo pela afoiteza das suas explicações e pelas soluções instantâneas que oferecia para fazer frente a Rosas. Ainda que estabeleça uma série de paralelismos com Amalia, uma novela política que narra acontecimentos dum passado imediato, a obra de Piglia exprime uma vontade de incorporar-se na literatura de fundação. Assim se abre, pois, uma nova etapa que vai do rosismo - e sinopticamente das Invasões Inglesas e da Campanha de Belgrano - ao terrorismo estatal da Junta militar de 1976. Às interrogações acerca dos antagonismos ideológicos do século XIX se lhes sobrepõem interrogações sobre os sucessivos antagonismos do século XX. Porém, acima de tudo, o romance torna a fundar um modelo literário para explicar a política de uma época. E, graças a um princípio de reiteração semântica, que exibe o significado da obra em função do qual esses atributos existem e demonstram a sua pertinência estética, esse caráter de fundação revelase repetidas vezes nos variegados procedimentos da sua mise en abyme. Assim, Renzi pretende escrever La prolijidad de lo real como um relato familiar que seja ao mesmo tempo um relato nacional. Este processo de alegorização familiar, que abunda na literatura hispano-americana do século XIX e princípios do XX, é posto em prática em Respiração artificial na genealogia dos três Ossorios, fortemente ligados à história argentina (o rosismo, o ciclo de 1880 de curta duração e o ciclo atual até ao momento de enunciação do relato, 1979). O primeiro Ossorio é, ademais, um personagem intratextual e intertextual. Com efeito, ao explorar o quarto de Maggi, o historiador, o seu sobrinho Renzi se depara com os seguintes livros: Vida de Juan Manuel de Rosas a través de su correspondencia, de Irazusta. Los antecedentes de Pedro de Angelis, de Ignacio Weiss, La vida cotidiana en los Estados Unidos (1830-1860), de Robert Lacour, Alberdi y su tiempo, de Mayer etc.*

Todos estes livros constituem um valioso material para a reconstrução histórica que Marcelo estava tentando fazer a pro- 
pósito do itinerário de Enrique Ossorio. Há uma simbiose histórica entre as épocas e os seus protagonistas que Enrique Ossorio, o desterrado, tenta empreender escrupulosamente: propõe-se escrever no século XIX uma novela utópica que decorra em 1979, quer dizer, como um espelho que reflita o terror argentino do rosismo, incluindo o do yrigoyenismo e o dos anos do Processo: 15-7-1850 - La utopía de un soñador moderno debe diferenciarse de las reglas clásicas del género en un punto esencial: negarse a construir un lugar inexistente. Entonces: diferencia clave. no situar la utopía en un lugar imaginario, desconocido (el caso más común: una isla). Darse en cambio cita con el propio país, en una fecha (1979) que está, sí, en una lejanía fantástica. No hay tal lugar: en el tiempo. Aún no hay tal lugar. Esto equivale para mí al punto de vista utópico. Imaginar la Argentina tal cual va a ser dentro de 130 años: ejercicio cotidiano de nostalgia, roman philosophique*.

Respiración artificial evoca a Alberdi de um modo ao mesmo tempo crucial e problemático. Como demonstrou José Sazbón, o personagem de Enrique Ossorio - "una representación del mismo Alberdi como el gran desterrado de la historia argentina" e amigo seu na ficção - reproduz a sua situación histórica "como secretario de Lavalle en 1839, su formación intelectual con predominio de historicismo, su composición de una novela filosófica, Peregrinación de Luz del día...”*. Na Argentina, o pensamento utópico que encontra em Alberdi um dos seus maiores exponentes, longe de ser produto de uma descrença na História, como argúem certas posturas pós-modernas, seria pelo contrário o resultado da crítica à modernidade latino-americana e aos projetos nacionais a que dera lugar. Em Respiração artificial esta incessante e pungente contestação da História, herdeira do iluminismo europeu, incorpora os paradoxos e as contradições que engendra: é a maneira com que a literatura se oferece como forma de autoconhecimento.

A maestria com que Piglia maneja em Respiración artificial as técnicas estilísticas associadas à estética pós-moderna e a singularidade das correntes pós-modernas latino-americanas perante as ocidentais ${ }^{5}$ já foram suficientemente abordadas. O que se procura fazer aqui é descrever e compreender o dina-

${ }^{5}$ As pós-modernidades latino-americanas se manifestam com um referente político concreto: confrontar a tese de Colás, que segue Yúdice, ou a de Bratosevich, que segue Irlemar Chiampi, e a Julio Ramos, sobre o barroco latino-americano.
"(: 104)

" (De Grandis. Polémica y estrategias narrativas en América Latina. Op. cit.: 132) 
• (Piglia, Ricardo.“Una pro. puesta para el próximo mi. lenio." Em: Argentinos: retra. tos de fin de milenio. Viva. La revista de Clarín. Buenos Aires, 1999: 166-167) mismo da "imaginação" nacional e o estilo, num sentido amplo, da sua literatura. Este estilo está composto de fragmentos do discurso social e de códigos culturais e políticos próprios, por meio dos quais essa literatura se imagina a si mesma e estabelece uma espécie de autoconhecimento. Respiración artificial põe outra vez em funcionamento o macro-texto cultural e político do século XIX, que abarca os seus textos canônicos, literários, políticos e filosóficos, encetando um novo diálogo entre esse passado e o presente. Mediante o século XIX se reintegra o papel principal que desempenhavam as relações entre literatura e política, o que neste contexto significa que o romance deve ser lido como uma interrogação constante e como uma operação contra a linguagem autoritária, contra a linguagem monológica do Estado. Esta estetização crítica da política, longe de contribuir para garantir a harmonia e a coesão da comunidade imaginada, é uma chamada à sua contestação. Em "Política y ficción: un entrevero argentino", Piglia afirma que esses dois termos são antagônicos: "La literatura trabaja la política como conspiración, como guerra; la política como gran máquina paranoica y ficcional. Eso es lo que uno encuentra en Sarmiento, en Hernández, en Macedonio, en Lugones, en Roberto Arlt, en Manuel Puig... En la historia argentina la política y la ficción se entreveran y se desvalijan mutuamente, son dos universos a la vez irreconciliables y simétricos"*.

Assim, em Respiración artificial o entrelaçamento de textos e reflexões sobre o século XIX não se oferece como elemento de identidade ontológica, mas antes como um referente saturado de textos a partir dos quais se examinam os entrecruzamentos em que se recodificam as apropriações de domínios literários alheios e começam a desempenhar uma nova função local, explicáveis à base de conjunturas sociais e históricas concretas.

Em "Una propuesta para el próximo milenio", Ricardo Piglia reflete sobre como se escreve ou re-escreve a História nos alvores do século XXI. Retoma o título de Seis propostas para o próximo milénio, que Italo Calvino preparara para uma série de conferências na Universidade de Harvard. Finalmente "las seis propuestas previstas (la levedad, la rapidez, la exactitud, la visibilidad, la multiplicidad...) quedaron reducidas a cinco, que son las que se encontraron escritas después de la muerte de Calvino”* . Piglia propõe-se escrever a que falta: “ ¿Cuál sería la sexta propuesta no escrita para el próximo milenio?”* . O aspecto 
fundamental da sua pergunta é que ela se situa num território marginal, um subúrbio (outra vez a evocação borgeana e a idéia da modernidade periférica de Beatriz Sarlo). ¿`Y cuál sería esa propuesta escrita desde Buenos Aires, escrita desde este suburbio del mundo? Cómo veríamos nosotros el futuro de la literatura o la literatura del futuro y su función?’”. Piglia volta a expor a questão nacional a partir da literatura e duma localidade que possibilita uma visão "específica", "al sesgo", "desde el borde de las tradiciones centrales"*. E esse lugar excêntrico lhe daria a vantagem suplementar de imaginar uma literatura especulativa, uma espécie de "versión utópica de Pierre Menard, autor del Quijote."

Não se trata tanto de "cómo reescribiríamos literalmente una obra del passado" senão - e aqui Piglia regressa a Macedonio Fernández e à utopia - de "cómo reescribiríamos imaginariamente la obra maestra futura”* . E a função utópica da literatura serviria para assenhorear-se desse lugar-limite onde a linguagem se despedaça e se desvanece em silêncio, em ausência de linguagem. Nesse lugar polissêmico, Piglia alude aos anos do Processo, porquanto escrever sobre a Argentina "nos enfrenta con los límites de la literatura”; entre esses limites encontra-se aquele que impõe o horror da repressão clandestina - "una experiencia que a menudo parece estar más allá del lenguaje”-, como se a linguagem por sua vez tivesse um limite, "una frontera después de la cual está el silencio”.

Muitos escritores do século XX defrontaram-se com esta questão: "Beckett, Kafka, Primo Levi, Ana Ajmatova, Marina Tzvetaieva, Paul Celan. La experiencia de los campos de concentración, la experiencia del Gulag, la experiencia del genocidio. La literatura prueba que hay acontecimientos que son muy difíciles, casi imposibles de transmitir; supone una relación nueva con el lenguaje de los límites"*. Para ilustrar esta experiência, Piglia reconhece em Rodolfo Walsh o escritor nacional que dá um nome a esse limite: "Walsh escribe: 'Hoy en el tren un hombre decía 'Sufro mucho, quisiera acostarme a dormir y despertarme dentro de un año.' Y concluye Walsh: 'hablaba por él pero también por mí”**. Nessa moção de dar a palavra a outro pode-se relatar o "punto ciego de la experiencia," e nele se instaura a idéia de deslocação e de distância que, segundo Piglia, se convertem numa lição de história e também de estilo porque "condensa $[\mathrm{n}]$ un sentido múltiple en una sola escena y en una 
voz" de onde se pode reescrever a história da experiência. Esta seria a sexta proposta que Piglia acrescentaria às de Calvino: a idéia de deslocamento e de distância. Se por estilo entendemos como movimento até essa outra enunciação, a literatura seria então "el lugar en el que siempre es otro el que viene a decir: 'Yo soy otro,' como dizia Rimbaud*.

Deslocamento e distância, experiência e terror, eis os elementos fundamentais da sua sexta proposta, e dos discursos críticos e literários com que edifica alegorias repassadas de significações codificadas e convertidas em patrimônio da literatura nacional. A insistência com que Piglia se acerca à experiência do horror descreve uma condição (uma formação sintomatológica?), já que alude aos excluídos e às exigências impostas pela cultura da nossa época que quase nos força a viver sem parâmetros e sem memória, submersos na velocidade vertiginosa da informação e comunicação eletrônica em que o tempo se funde no instante mesmo em que põe em perigo a literatura e o autor:

En el año 2100, cuando el nombre de todos los autores se haya perdido y la literatura sea intemporal y sea anónima, esta pequeña propuesta [...] será, tal vez, un web.site llamado Las seis propuestas que para ese entonces serán leídas como si fueran consignas en un antiguo manual de estrategia usado para sobrevivir en tiempos difíciles*.

Paradoxalmente, e nestes difíceis tempos, em Seis propuestas para el próximo milenio Piglia faz mais uma vez um chamamento à literatura nacional e à sua territorialidade específica, ao autor como o narrador benjaminiano da experiência que garanta a sobrevivência da comunidade; e, ao mesmo tempo, vaticine o desaparecimento do autor.

Como relato de fundação, Respiración artificialpermite esse enraizamento numa comunidade nacional, posta em crise e em risco pelas democracias globalizadas. Nos fins do século XX, como sucedera no século XIX, as relações entre estado e nação, democracia e governo, cultura e literatura tornam-se objeto de importantes debates nas esferas intelectuais. Nesses debates impõe-se outra vez uma questão de limites. Fica assim aberta uma brecha, uma berma, uma fronteira entre a máquina do atual estado neoliberal e democrático, repressivo e exclusivista, e a imaginação nacional cuja última etapa de fundação teve lugar no estado terrorista dos anos 1970, cuja profunda marca 
continua sendo ignorada pelo neoliberalismo. Mas a violência renasce sob novas formas. Quem escreverá então e que modalidades assumirá o relato fundador da experiência democrática finissecular, das suas violências e intolerâncias? Entre os escritores e os críticos convertidos em profissionais da engrenagem cultural, ou acadêmicos, abre-se outra brecha, outra berma, outra fronteira por transpor e que consiste na resistência contra a integração e no esforço incessante de dar um nome a esse Outro anônimo e murmurante sempre presente nos múltiplos e entrelaçados discursos sociais em que estamos todos imersos.

Tradução

Maria do Carmo Cardoso (UFRJ)

Mario Pinho (UBC) 
Palavras-chave Literatura argentina Estado moderno Literatura e política Keywords Argentinean literature Modern State Literature and politics

\section{Rita de Grandis}

Doutora em Letras Hispânicas pela Universidade de Montreal. Titular de literatura hispano-americana na Universidade da Columbia Britânica (Vancouver, Canadá). Autora de Polémica y estrategias narrativas en América Latina (Beatriz Viterbo Editora, 1993), co-autora junto com Zilá Bernd de Imprevisíveis Américas: questões de hibridação cultural nas Américas (Porto Alegre, Sagra-D.C. Luzzatto Editores, 1995) e de Unforseeable Americas: questioning cultural hybridity in the Americas (Amsterdam: Rodopi, 1999). Editora convidada de "María Luisa Bemberg: entre lo político y lo personal” (Revista Canadiense de Estudios Hispánicos. Vol. XXVII, n 1, Otoño 2002); e de "Eva Perón. Variations on a myth" (Journal of the Canadian Association of Latin American and Caribbean Studies, vol. 24, $\mathrm{n}^{\circ}$ 48, 1999). Publicou inúmeros artigos em revistas internacionais e volumes coletivos.

\section{Resumo}

Tanto dentro quanto fora da Argentina, a significação de Respiración artificial foi analisada, nas décadas de 1980 e 1990, em relação aos horrores do panóptico do Estado terrorista argentino (1976-1983). Voltar a Respiración artificial no início do século XXI implica situar a sua leitura não mais como uma resposta cifrada do Proceso, mas sim na lógica da dinâmica particular que a literatura nacional adquiriu no novo contexto histórico, caracterizado pela continuidade, consolidação e crise dos processos democráticos internos, no quadro internacional da hegemonia de uma economia de câmbio livre de corte neoliberal que afeta de modo singular o desenvolvimento das democracias locais e de suas literaturas. Desde essa nova conjuntura histórica, a presença do século XIX em Respiración artificial permite inscrever e conectar o presente de seu contexto de produção e enunciação - final da década de 1970 - com as origens do Estado moderno. Esse século XIX pode ser lido como chave para uma crítica da racionalidade moderna periférica.

\section{Abstract}

In the 1980's and 1990's, in Argentina and outside it, Artificial Respiration was analyzed in relation to the horrors of the terrorist State's "panopticom” (1976-1983). To revisit Artificial Respiration at the beginning of the $21^{\text {st }}$ century implies to situate our reading no longer as a coded reply to the Proceso, but rather as a particular

\section{Resumen}

Tanto en Argentina como en el exterior la significación de Respiración artificial fue analizada, durante las décadas del 1980 y 1990, en relación a los horrores del "panopticom" del Estado terrorista argentino (1976-1983). Volver a Respiración Artificial a comienzos del siglo XXI implica situar su lectura ya no como una 
aesthetic response of national literature to a new historical context, characterized by the continuation, consolidation and crisis of the democratic process, under the hegemony of neoliberalism. This new situation affects the development of local democracies and their literatures in very specific ways. Within this timeframe the presence of the $19^{\text {th }}$ century in Artificial Respiration inscribes and connects the present of its context of enunciation - end of the 1970's - with the origins of the modern state as a critique of modern peripheral rationality. respuesta cifrada del Proceso, sino dentro de la dinámica particular que la literatura nacional adquirió en el nuevo contexto histórico, caracterizado por la continuación, consolidación y crisis de los procesos democráticos internos en el cuadro internacional de la hegemonía de una economía de librecambio de corte neoliberal que afecta de un modo singular el desarrollo de las democracias locales y de sus literaturas. Desde esa nueva coyuntura histórica, la presencia del siglo XIX en Respiración artificial permite inscribir y conectar el presente de su contexto de producción y enunciación - final de la década de 1970 - com los orígenes del Estado moderno. Ese siglo XIX puede ser leído como clave para una crítica de la racionalidad moderna periférica.
Recebido em 28/01/2003 Aprovado em 12/07/2003 